\title{
Courtship learning in Drosophila melanogaster: Diverse plasticity of a reproductive behavior
}

\author{
Leslie C. Griffith ${ }^{1,3}$ and Aki Ejima ${ }^{2}$ \\ ${ }^{1}$ Department of Biology, National Center for Behavioral Genomics and Volen Center for Complex Systems, Brandeis University, \\ Waltham, Massachusetts 02493, USA; ${ }^{2}$ Career-Path Promotion Unit for Young Life Scientists, Kyoto University, Kyoto, Japan \\ 606-8501
}

\begin{abstract}
Mechanisms for identifying appropriate mating partners are critical for species propagation. In many species, the male uses multiple sensory modalities to search for females and to subsequently determine if they are fit and receptive. Males can also use the information they acquire in this process to change their courtship behavior and reduce courtship of classes of targets that are inappropriate or unreceptive. In Drosophila, courtship plasticity, in the form of both nonassociative and associative learning, has been documented-the type of learning depending on the nature of the trainer. The conditions in which the male is presented with the training target can profoundly alter the cues that he finds salient and the longevity of the memory that he forms. With the exception of habituation and sensitization, these types of plasticity have an operant component in that the male must be courting to respond to the behavior-altering cues. Courtship plasticity is therefore a complex and rich range of behaviors rather than a single entity. Our understanding of these plastic behaviors has been enhanced by recent advances in our understanding of the circuitry underlying courtship itself and the identification of chemical cues that drive and modify the behavior. Courtship learning is providing a window into how animals can use a variety of sensory inputs to modulate a decision making process at many levels.
\end{abstract}

When confronted with a potential mate, Drosophila melanogaster males perform a stereotyped courtship ritual. This behavior serves at least two obvious functions for the male. The first is to prime conspecific females for copulation. During courtship, the female is assessing the male's suitability, and if the song he sings (Burnet et al. 1971; von Schilcher 1976a) and pheromones he emits (Grillet et al. 2006; Kurtovic et al. 2007) are correct for her species and of sufficient quality, her willingness to copulate is increased. She will slow her locomotion, present her abdomen to the male, and then spread her wings and genital plates to allow him to mount (Lasbleiz et al. 2006). A second function of courtship is that it allows a male to accumulate information about the target courtship object to assess its suitability and receptiveness. The male uses auditory, mechanosensory, visual, and chemosensory signals from the target to make this assessment (for review, see Villella and Hall 2008; Ejima and Griffith 2009).

Since D. melanogaster males will avidly initiate courtship of a wide variety of inappropriate and/or unreceptive targets, including immature males, sexually immature virgin females, mated females, and heterospecific females, the information obtained during courtship is critical to deciding whether to increase the intensity of his effort or terminate pursuit of the target. In the last several years, courtship has become a favored model for those researchers interested in how the nervous system specifies "innate" behaviors. While it is true that a male does not have to be instructed to produce adequate courtship (Hall 1994; Clyne and Miesenbock 2008), this apparently stereotyped behavior is far from static: It can be modified in a dizzying number of ways by experience. In this paper, we will discuss how information gathered during courtship can allow males to learn about specific types of courtship objects and broadly modify future behavioral responses to a particular class of target.

\footnotetext{
${ }^{3}$ Corresponding author.
}

E-mail griffith@brandeis.edu; fax (781) 736-3107.

Article is online at http://www.learnmem.org/cgi/doi/10.1101/lm.956309.

\section{Courtship behavior engages multiple sensory systems}

Courtship behavior in D. melanogaster toward a female is easily recognized and quantified; it consists of sub-behaviors that are performed in an ordered manner (Bastock and Manning 1955; Hall 1994). Each of these activities provides the male with an opportunity to obtain sensory information about the target. The male uses visual cues, olfactory cues, and auditory information to initiate contact with potential mates (Ejima et al. 2005; Ejima and Griffith 2008). The invariant order of subsequent behaviors, and studies in which particular sensory pathways are blocked, suggest the following model for interaction of the male with the courtship target. Once the male is in proximity of a female, the first observable courtship behavior is orientation toward the target. Orientation and following at close range allows the male to potentially sense airborne pheromones of low volatility (Ferveur 2005). Once he has located a female, he taps her abdomen with his foreleg. This could provide a mechanosensory stimulus to the female, but could also allow the male to sample nonvolatile cuticular pheromones with chemosensory organs on his foreleg (Bray and Amrein 2003). Tapping is followed by wing extension and vibration to produce a courtship song. The structure of the song is species-specific and allows the female to identify the male as appropriate (for review, see Tauber and Eberl 2003) in addition to increasing her receptivity. The song also has autoerotic effects on the male, increasing his courtship enthusiasm toward other flies (von Schilcher 1976b; Eberl et al. 1997). After the orientation, following and singing sub-behaviors are performed for a whiletypically a minute or more-then the male applies his proboscis to the female's genitalia, sampling a potentially different set of nonvolatile pheromones with his gustatory sensory system. The male may then attempt to mount several times before he finally successfully copulates. These final steps also could involve mechanosensory stimulation of both participants since the genitalia are rife with mechanosensory bristles (Ejima and Griffith 2008).

It is surmised that during these detailed steps, both male and female flies are accumulating and potentially integrating multiple 
different types of sensory information during a sexual encounter (Markow 1987; Krstic et al. 2009). In the century since curious scientists started watching the sex life of the fly, many studies have been aimed at understanding which sensory systems are used to drive the courtship process itself and the plastic aspects of the behavior. Perhaps unsurprisingly, not all studies agree on the relative importance of particular sensory systems. While in some cases discrepancies have to do with pleiotropy in the effects of mutations or the expression patterns of transgenes, the specific differences between studies can often be explained by differences in the conditions under which the behavioral observation was carried out (Ejima and Griffith 2008; Krstic et al. 2009). Courtship does not uniquely depend on a particular sensory input: Elimination of any individual sensory modality will not eliminate courtship (Ejima et al. 2005; Krstic et al. 2009); only close to complete sensory deprivation reduces courtship to near zero (Gailey et al. 1986), implying that in D. melanogaster the behavior is redundantly driven.

Given that the male can use multiple cues to initiate and maintain courtship, factors like light conditions and chamber size can easily affect the salience of particular cues and the hierarchy of sensory systems engaged. An example is chamber size: Small chambers might enhance the role of chemical cues that are of low volatility or could have an influence on arousal state or stress level. For locomotor activity, even the shape of the chamber can have an impact on performance (N Donelson and LC Griffith, unpubl.). Light is equally important. No light, or dim red light, forces the male to rely on nonvisual cues. It is important to emphasize that there is no "right" chamber size or light level: Flies will court under a variety of conditions, but how they do it and what they are paying attention to and learning from will be different. This poses a challenge to investigators to interpret their results from the point of view of what the fly actually experienced. Meeting this challenge will provide a rich picture of these robust and robustly plastic behaviors.

In the following sections, and as summarized for female (or feminized-male) trainers/testers in Tables 1 and 2, we discuss the major types of plasticity that have been observed in courtship, with attention to what is known about the sensory cues that are capable of producing behavioral modifications and, where known, the neuronal and molecular circuitry that is involved.

\section{Suppression of courtship behavior toward females after exposure to mated females: Associative learning}

The first report of learning related to courtship behavior was the finding that exposure of mature males to a previously mated female for $1 \mathrm{~h}$ led to a suppression of courtship toward virgin females that lasted for 2-3 h (Siegel and Hall 1979). This behavioral paradigm, often called "courtship conditioning" or "conditioned courtship suppression," has become widely used, and the mechanisms of formation of memory of mated females have been investigated both at the level of learning theory and at the cellular and molecular levels.

Is courtship conditioning really learning? The most simple explanation for Siegel and Hall's observation is that mated females

Table 1. Summary of learning and memory paradigm conditions and mechanisms

\begin{tabular}{|c|c|c|c|c|}
\hline Memory & $\begin{array}{l}\text { Chamber size } \\
\left(\mathrm{cm}^{3}\right)\end{array}$ & $\begin{array}{l}\text { Lighting } \\
\text { conditions }\end{array}$ & $\begin{array}{l}\text { Responsible gene/brain } \\
\text { region }^{\mathrm{a}}\end{array}$ & References \\
\hline STM & 0.4 & on & $a m n$ & Siegel and Hall 1979 \\
\hline STM & 0.4 & on/off & olfC, $s b l$ & Tompkins et al. 1983 \\
\hline STM & 0.4 & on & $d n c, a m n, c a b, r u t, t u r$ & Gailey et al. 1984 \\
\hline STM & 0.4 & on & eag, Sh & Cowan and Siegel 1984 \\
\hline STM & 0.4 & on & $d n c, a m n$ & Ackerman and Siegel 1986 \\
\hline STM & 0.2 & on & & Zawistowski 1988 \\
\hline STM & 0.15 & on & CaMKII & Griffith et al. 1993 \\
\hline STM & 0.15 & on/off & CaMKII, MB, AL, CC, LP & Joiner and Griffith 1997, 1999, 2000 \\
\hline STM & 0.15 & on & $P K C$ & Kane et al. 1997 \\
\hline STM & 1.45 & on & PKA & O'Dell et al. 1999 \\
\hline STM & 0.1 & on & $M B(A L)$ & McBride et al. 1999 \\
\hline STM & 0.88 & on & $c d$ & Savvateeva et al. 2000 \\
\hline STM & 0.18 & on & homer & Diagana et al. 2002 \\
\hline STM & 0.3 & on & & Reif et al. 2002 \\
\hline STM & 0.88 & on & CaMKII & Broughton et al. 2003 \\
\hline STM & 0.88 & on & $\mathrm{CC}, \mathrm{MB}$ & Sitnik et al. 2003 \\
\hline STM & 0.15 & off & CaMKII, AL, MB & Mehren and Griffith 2004, 2006 \\
\hline STM & 0.1 & on & dfmr1 & McBride et al. 2005 \\
\hline STM & 3.5 & on & & Siwicki et al. 2005 \\
\hline STM & 0.15 & off & $d n c, a m n$ & Ejima et al. 2005 \\
\hline STM & 40 & on & & Dukas 2005 \\
\hline STM + MTM & 0.88 & on & nemy & Kamyshev et al. 1999, 2000, 2002 \\
\hline STM + MTM & 0.88 & on & lat, rut, dnc, amn & Bragina and Kamyshev 2003 \\
\hline LTM & 8 & on & $\mathrm{MB}$ & McBride et al. 1999 \\
\hline LTM & 0.88 & on & per, rut, dnc, DCO, amn & Sakai et al. 2004 \\
\hline LTM & 8.48 & on & Notch & Presente et al. 2004 \\
\hline LTM & food tube & on & & Ganguly-Fitzgerald et al. 2006 \\
\hline LTM & food chamber & on & Orb2 & Keleman et al. 2007 \\
\hline LTM & food tube & on & bs & Donlea et al. 2009 \\
\hline LTM & 0.88 & on & $E \subset R$ & Ishimoto et al. 2009 \\
\hline
\end{tabular}

${ }^{a}$ These regions comprise the postulated olfactory learning circuit. Primary sensory neurons enter the AL and synapse on local interneurons and neurons that project to LP and MB. MBs are comprised of $\alpha / \alpha^{\prime}, \beta / \beta^{\prime}$, and $\gamma$ lobe neuropils, each of which have been implicated in different behaviors and/or different temporal epochs of olfactory learning (for review, see Berry et al. 2008). Connection of this olfactory processing circuitry to the CC, a motor output locus (Strauss 2002), is postulated to be the effector for changes in behavior. Studies used female or feminized-male trainers.

(LTM) Long-term memory; (STM) short-term memory; (MB) mushroom bodies; (AL) antennal lobe; (CC) central complex; (LP) lateral protocerebrum. 
Table 2. Summary of trainer/tester combinations used in studies in Table 1

\begin{tabular}{|c|c|c|c|c|}
\hline Trainer & Tester & STM & MTM & LTM \\
\hline \multirow[t]{6}{*}{ Mated } & mated & $\begin{array}{l}\text { Joiner and Griffith 1997, 1999, 2000; } \\
\text { Kane et al. 1997; Savvateeva et al. 2000; } \\
\text { Sitnik et al. 2003; Dukas } 2005\end{array}$ & $\begin{array}{l}\text { Kamyshev et al. 1999, } \\
\text { 2000, 2002; Bragina } \\
\text { and Kamyshev } 2003\end{array}$ & Keleman et al. 2007 \\
\hline & mated-immobile & $\begin{array}{l}\text { Ejima et al. 2005; Kamyshev et al. } \\
\text { 1999, 2000, } 2002\end{array}$ & & \\
\hline & virgin & $\begin{array}{l}\text { Kane et al. 1997; O’Dell et al. 1999; } \\
\text { McBride et al. 1999, 2005; Reif et al. 2002; } \\
\text { Dukas } 2005\end{array}$ & & $\begin{array}{l}\text { McBride et al. 1999; } \\
\text { Presente et al. } 2004\end{array}$ \\
\hline & virgin-immobile & $\begin{array}{l}\text { Siegel and Hall 1979; Tompkins et al. 1983; } \\
\text { Gailey et al. 1984; Cowan and Siegel 1984; } \\
\text { Zawistowski 1988; Griffith et al. 1993; } \\
\text { Joiner and Griffith 1997, 1999, 2000; } \\
\text { Diagana et al. 2002; Mehren and Griffith 2004, } \\
\text { 2006; Siwicki et al. 2005; Ejima et al. 2005; } \\
\text { Kamyshev et al. 1999, 2000, 2002; Bragina } \\
\text { and Kamyshev 2003 }\end{array}$ & & $\begin{array}{l}\text { Sakai et al. 2004; } \\
\quad \text { Ishimoto et al. } 2009\end{array}$ \\
\hline & feminized male & Siwicki et al. 2005 & & \\
\hline & $\begin{array}{l}\text { immature } \\
\text { virgin-immobile }\end{array}$ & Ejima et al. 2005 & & \\
\hline \multirow[t]{5}{*}{ Immature virgin } & mated & Dukas 2005 & & \\
\hline & mated-immobile & Ejima et al. 2005 & & \\
\hline & virgin & Dukas 2005 & & \\
\hline & virgin-immobile & Ejima et al. 2005 & & \\
\hline & $\begin{array}{l}\text { immature } \\
\text { virgin-immobile }\end{array}$ & Ejima et al. 2005 & & \\
\hline \multirow[t]{3}{*}{ Virgin-immobile } & mated-immobile & Ejima et al. 2005 & & \\
\hline & virgin-immobile & Ejima et al. 2005 & & \\
\hline & $\begin{array}{l}\text { immature } \\
\text { virgin-immobile }\end{array}$ & Ejima et al. 2005 & & \\
\hline \multirow[t]{2}{*}{$\begin{array}{l}\text { Immature } \\
\text { virgin + odor }\end{array}$} & virgin-immobile & $\begin{array}{l}\text { Tompkins et al. 1983; Ackerman and Siegel 1986; } \\
\text { Zawistowski 1988; Ejima et al. } 2005\end{array}$ & & \\
\hline & male + odor & Broughton et al. 2003 & & \\
\hline Feminized male & virgin & & & $\begin{array}{l}\text { Ganguly-Fitzgerald et al. 2006; } \\
\text { Donlea et al. } 2009\end{array}$ \\
\hline
\end{tabular}

(STM) Short-term memory; (MTM) medium-term memory; (LTM) long-term memory.

produce some sort of antiaphrodisiac compound that directly switches off courtship; however, several lines of evidence suggest that this is not the case. First, presentation of an extract of mated female alone does not produce a change in subsequent courtship behavior (Tompkins et al. 1983; Ackerman and Siegel 1986; Ejima et al. 2007). If mated females had an antiaphrodisiac, the compound alone should cause a cessation of all courtship. This finding also highlights a very salient feature of most of the courtship learning paradigms: To learn, the male must engage in courtship behavior toward some target. The "operant" aspect of these paradigms is poorly understood, but it is clear that without sufficient engagement of the mated female during the training phase, there is no change in behavior (Siegel and Hall 1979). Second, not all courtship behavior is affected by mated female training. Males are considered mature from both the behavioral and pheromonal point of view by 4-5 d after eclosion (Spieth 1974; Jallon 1984). Mature males will court several different, pheromonally distinct types of targets (Tompkins et al. 1980; Wicker and Jallon 1995; Savarit et al. 1999; Ejima et al. 2005): immature males, immature females, mature female virgins, and mature mated females. Courtship conditioning produces a decrease only in courtship of female targets (Gailey et al. 1984). Third, mutant flies that were isolated based on their inability to learn to avoid odors paired with shock are also defective in learning from mated females (see Table 1), suggesting that higher-order processing is required for this plasticity. Fourth, pairing an extract from a mated female (Tompkins et al. 1983), a gratuitous aversive substance (quinine) (Ackerman and Siegel 1986), or an aversive pheromone (cis-vaccenyl acetate, cVA) (Zawistowski and Richmond 1986; Ejima et al. 2007), with a virgin female can produce generalized suppression of female courtship without affecting courtship of immature males. This argues strongly that a female-specific cue is being associated with an aversive stimulus, making this plasticity a form of associative learning.

The change in courtship toward a test female after training with a mated female is believed to be a measure of associative memory. In most organisms, the consolidation of memory occurs via multiple mechanisms that can be distinguished by their temporal, cellular, and molecular bases (McGaugh 2000; Margulies et al. 2005). Short-term memory (STM), lasting on the order of hours, is produced by single training trials or multiple training trials that are not separated in time. STM requires no transcriptional 
or translational changes in the cell. Long-term memory (LTM) is produced when multiple trials are separated by some rest period and requires transcription. In Siegel and Hall's description of courtship conditioning, memory only lasted for a couple hours, suggesting that it would fall into the category of STM. Training in this initial study was carried out in a small $\left(0.4 \mathrm{~cm}^{3}\right)$ chamber where the male would be in almost constant contact with the mated female. Manipulation of the training conditions by increasing the size of the chamber (which allows the male to occasionally "escape" the mated female, creating a rest period, see Table 1 ) or by periodically removing the mated female has been shown to generate a memory that can last up to $8 \mathrm{~d}$ (McBride et al. 1999). The percentage of time spent in courtship is lower in large chambers (e.g., 5-cm food tubes), and training therefore needs to be carried out for a longer total time in these paradigms than in the STM paradigm. This reinforces the idea that there needs to be some minimum amount of courtship of the mated female to facilitate learning. Interestingly, generation of LTM also appears to be enhanced by the presence of food (McBride et al. 1999), suggesting that food may alter the salience of one or more of the cues.

Another feature of this behavior is that the conditioned stimulus, the cue that the male is learning to ignore after his aversive experience with the mated female, is one that is common to all females. In the STM assay, the male can learn to avoid both mature and immature females as well as mated females (Ejima et al. 2005), and in the LTM assay, the male can learn to avoid both virgin (McBride et al. 1999; Sakai and Kidokoro 2002; Presente et al. 2004; Ishimoto et al. 2009) and mated (Keleman et al. 2007) females. The cue or cues that are being associated do not involve visual stimuli since memory formation does not require light or intact male visual pathways (Joiner and Griffith 2000). Female behavior is also dispensable since the testing can be done with decapitated or immobilized targets for either STM (Siegel and Hall 1979; Ejima et al. 2005) or LTM (Sakai et al. 2004; Ishimoto et al. 2009). These findings suggest that chemical cues are the principal conditioned stimuli.

But while males learn to suppress courtship of all females, the choice of what type of female to use as a tester can affect the apparent strength of memory revealed by the test. Using a mated female tester provides the conditioned stimulus, but it also provides the unconditioned stimulus. The increased magnitude of suppression seen with mated female testers is likely the result of "retraining" or "relearning" (Gailey et al. 1991; Kamyshev et al. 1999). In psychological terms, the male is exhibiting a phenomenon known as "savings" from the first training session, which allows him to express suppression at a stronger and more consistent level. This can be useful technically where the memory produced is weak, as in LTM assays (Keleman et al. 2007).

The nature of the general female conditioned stimulus chemical cue was investigated by Siwicki and colleagues (2005) using courtship targets with altered cuticular hydrocarbon profiles. They identified 9-pentacosene as a compound that is correlated with learning and is sufficient to act as a conditioned stimulus (Siwicki et al. 2005). They found the presence of 7-tricosene and 5-heptacosene also correlated with learning, although more weakly. All of these hydrocarbons are present on both mature and immature virgins, although mature females have significantly higher levels than immature virgins (Ejima et al. 2005). These multiple correlations suggest that males are capable of using a variety of chemical cues as conditioned stimuli, although perhaps individual compounds may have different efficacies in particular contexts.

The nature of the endogenous aversive cue, or unconditioned stimulus, has also been investigated, and has been controversial. Mated females can acquire cuticular hydrocarbons passively from mating partners, and these can inhibit courtship (Scott et al. 1988). One such antiaphrodisiac is 7-tricosene (Lacaille et al. 2007), which can even be transferred to virgins that have been courted but not copulated (Ejima et al. 2007). These surface hydrocarbons, however, have a limited lifetime on the mated female, perhaps because they are groomed off. Females isolated for $24 \mathrm{~h}$ after mating no longer have 7-tricosene on their cuticle, but they can still be used to train males to suppress courtship (Ejima et al. 2007). The likely reason for this is that mated females also receive a variety of substances from males in ejaculate that are retained in their reproductive tracts for longer periods. One such compound is cVA. This lipid is made predominantly in males (Butterworth 1969) and, when presented with a virgin female, is sufficient to produce generalized courtship suppression (Ejima et al. 2007). To date, cVA is best-characterized as a compound shown to be capable of acting as an unconditioned stimulus, but there are other long-lasting chemicals transferred from males that can also fulfill that role (Yew et al. 2009).

As for other forms of learning in Drosophila, genetic and cellular mechanisms have been explored for courtship conditioning. In the first description of courtship conditioning, it was shown that memory stability was reduced in amnesiac males (Siegel and Hall 1979), indicating that this form of memory was mechanistically similar to odor/shock associative learning and likely involved a cAMP signal transduction pathway (for review, see Tully et al. 1994). STM formation was also impaired in other mutants (dunce, rutabaga, and the poorly characterized mutants cabbage and turnip) that had been isolated based on defects in odor/shock conditioning (Gailey et al. 1984). Memory duration was affected by mutations in PKA-RI, the regulatory subunit for the cAMP-dependent protein kinase (PKA) (O'Dell et al. 1999). Subsequently, a variety of other learning, ion channel, and brain morphology mutants have been tested and found to be defective for STM (see Table 1). Dominant transgenic strategies have implicated protein kinase $\mathrm{C}$ (Kane et al. 1997) and $\mathrm{Ca}^{2+} /$ calmodulin-dependent protein kinase II (CaMKII) (Griffith et al. 1993) in STM. LTM has been shown to require ecdysone (Ishimoto et al. 2009) and Notch (Presente et al. 2004) signaling and the CPEB protein Orb2 (Keleman et al. 2007).

The circuitry underlying male courtship behavior per se has been heavily studied in the last several years and is intimately tied to expression of a male-specific form of the putative transcription factor fruitless (Manoli et al. 2005; Stockinger et al. 2005). The anatomical substrates of courtship learning have been investigated using both targeted manipulations of specific signal transduction pathways and targeted ablations of populations of neurons. Joiner and Griffith (1999) used the GAL4/UAS system (described in Duffy 2002) to drive expression of an inhibitor of CaMKII to map the anatomical requirement for this kinase in STM of courtship suppression. This protein kinase is an important player in many aspects of neuronal function and may have a particular role in memory formation because of its ability to become independent of its normal regulators following brief activation (Griffith 2004).

Using a collection of 18 lines, Joiner and Griffith (1999) found that mushroom bodies, lateral protocerebrum, and parts of the central complex all had roles in CaMKII-dependent memory formation under red lights, a condition under which the behavior is primarily driven by chemosensory cues. Lines that expressed in mushroom body $\gamma$-lobes appeared to have the strongest defects in memory. The defects in many of these brain regions were dependent on light conditions (Joiner and Griffith 2000). Defects in memory could be compensated for by allowing the male to have visual input during the training period (Joiner and Griffith 1997). These data indicate that males are capable of using separate molecular and possibly anatomical circuits for memory formation, depending on the available sensory input. 
This role for mushroom bodies is reminiscent of findings with odor/shock learning and is consistent with the known enrichment of "learning" gene expression in this neuropil (Davis 2005). McBride et al. (1999) explicitly investigated the need for mushroom bodies in STM by using chemical ablation. This study found that mushroom bodies were required for 30- and 60-min recall but not for immediate memory formation. Hydroxyurea ablation can also occasionally reduce antennal lobes, and in these animals, 30- but not 60-min memory was impaired. LTM (1-8 d after training) was eliminated by mushroom body ablation. In aggregate, these results suggested that memory is processed in several temporally distinct waves, with mushroom bodies being the final repository of LTM.

\section{Immediate suppression of courtship toward mated females: Nonassociative plasticity?}

As first conceived, the courtship conditioning assay consisted of two parts: an initial exposure to a mated female that delivered both conditioned and unconditioned stimuli, during which the male learned to associate the two cues, and a memory test with a female that presented only the conditioned stimulus. Observations of courtship activity during the training period showed that, while males court mated females with less vigor than they do virgins (Gailey et al. 1984), a comparison of courtship levels at the beginning and end of training revealed a time-dependent decrease in average courtship levels (Siegel and Hall 1979). The immediate suppression of courtship during training depends on CaMKII (Griffith et al. 1993), the ether-à-go-go potassium channel (Griffith et al. 1994), and protein kinase C (Kane et al. 1997).

The simplest mechanistic explanation for suppression of courtship during training is that the decrease in courtship was a real-time reflection of memory formation, i.e., learning. A logical extension of this idea is that memory formation should depend on the decrease in courtship during training. This supposition was shown to be untrue in two early studies of the molecular basis of mated female learning (Joiner and Griffith 1997; Kane et al. 1997), in which manipulation of signal transduction pathways could totally eliminate the decrease in courtship during training but left memory formation intact. A resolution to this conundrum was suggested by circuit mapping experiments using the CaMKII inhibitor peptide. In these studies, investigators found that the behavior during training was anatomically dissociable from memory, i.e., GAL4 lines that disrupted behavior during training did not necessarily disrupt memory (Joiner and Griffith 1999). These data indicated that the change in behavior during training was independent of associative memory formation.

In the case of fast courtship suppression, the brain region most strongly requiring CaMKII activity was the antennal lobe. Suppression during training was decreased by inhibition of CaMKII activity in cells that innervated the antennal lobes (Joiner and Griffith 1999) and was enhanced by expression of constitutively active CaMKII in cholinergic antennal lobe inputs (Mehren and Griffith 2004, 2006). These cells could be either projection neurons (which connect the antennal lobe to the mushroom bodies and lateral protocerebrum) or excitatory local neurons, both of which are cholinergic in the insect and downstream from olfactory receptor neurons. Plasticity in these neurons probably reflects integration of olfactory cues, and these neurons have to be connected into basic courtship circuitry. The results of these studies are also consistent with the global idea that for all types of olfactory memory there is an initial antennal lobe plasticity that is then consolidated into a mushroom body memory (Berry et al. 2008), but also suggest that there may be multiple independent forms of early plasticity.

The relevant upstream olfactory neurons are likely to be responsive to endogenous fly odors or pheromones. Only four $\mathrm{Or}$ gene products respond to fly odors: Or47b and Or88a, which respond to both male and female odors, and Or65a and Or67d, which respond to cVA (van der Goes van Naters and Carlson 2007). The response to the mated female can be mimicked by presenting the odor of cVA with a virgin female. Both Or65a (Ejima et al. 2007) and Or67d (Kurtovic et al. 2007) have been shown to be important for mediating courtship inhibitory effects of cVA. The large amount of work in recent years on the basic circuitry of courtship should help unravel the cellular mechanisms of this plasticity.

\section{Suppression of courtship behavior after exposure to virgin females: Associative learning}

For many years it was believed that suppression of courtship of female Drosophila could only be produced by exposure to mated females. In their original description of the behavior, Siegel and Hall (1979) did a control training session with mature virgins and saw no learning. In this experiment, however, 20/24 males copulated with the virgin trainer. Subsequent work has shown that copulation blocks the ability of males to learn to suppress courtship (Ejima et al. 2005), suggesting that this control did not address the specificity issue. In the following years, investigators moved toward using a control training session with an immature virgin (first done by Tompkins et al. [1983]). Immature virgins are highly attractive, but like mated females, actively reject male advances. Training with an immature virgin did not produce any memory when males were tested using an anesthetized mature virgin as a courtship target. This procedure was followed exactly by many other researchers, and the conclusion that was drawn by the field was that exposure to "a virgin female" did not affect subsequent courtship.

It turns out that the situation is not so simple. Exposure of males to virgin females (of any age) does indeed fail to induce the generalized suppression of female courtship that training with a mated female does. What was not appreciated at the time, however, was that males could use age-dependent differences in pheromonal profile to learn to avoid females of a specific age. Ejima et al. (2005) found that training males with either a mature or an immature virgin could, in fact, cause modification of male courtship behavior: Males would avoid courtship of that age class of female but would readily court either older or younger females.

The memory formed was associative, and age-specific volatile cuticular compounds served as the conditioned stimuli. Pairing hexane extracts of virgins of a particular age with a courtship object was sufficient to create a memory of the encounter as long as the male did not copulate with the courtship object. Copulation was shown to prevent memory formation, indicating that the aversive experience of not copulating after courtship was acting as the unconditioned stimulus. Formation and stability of memory in this paradigm was, like with mated female training, sensitive to mutations in either dunce or amnesiac (Ejima et al. 2005). While the initial experiments demonstrating this type of memory were done in a manner that resulted in formation of STM only (small chambers, single training trial), LTM can also be seen $24 \mathrm{~h}$ after spaced training with a decapitated mature virgin $(3 \times 1 \mathrm{~h}$ in tubes with food) (N Donelson and LC Griffith, unpubl.).

\section{Suppression of young male courtship: Habituation}

Naïve mature males will initiate vigorous courtship and even attempt to copulate with immature (less than $1 \mathrm{~d}$ old) males (Cook and Cook 1975; Jallon and Hotta 1979; Tompkins et al. 1980). The intensity of courtship of young males wanes over time, decreasing to about half its initial level within $30 \mathrm{~min}$ (Gailey et al. 1982). Males exposed to young males in this way will have greatly reduced 
courtship of a subsequently presented immature male. This aftereffect lasts for several hours and is specific; courtship of females is unaffected (Gailey et al. 1982). Conversely, exposure to mated females, which induces a general suppression of courtship toward all types of females, does not affect courtship of young males (Gailey et al. 1984). While courtship of young males is clearly "nonproductive" with regard to procreation, plasticity in this behavior was postulated (Zawistowski and Richmond 1985) and demonstrated (Gailey et al. 1985) to confer a fitness advantage in subsequent mating with females in the presence of young males.

Courtship suppression after exposure to young males is believed to be a form of habituation, since it can be produced simply by exposure of mature males to immature male substances. A chamber that has previously housed young males (Gailey et al. 1982), filters containing synthetic young male hydrocarbons (Vaias et al. 1993), or filters containing a hexane extract of young male cuticle (Ejima et al. 2005) can cause a decrease in the courtship of a subsequently presented immature male. Another piece of evidence that this type of learning is habituation is that it can be reversed by a strong, unrelated stimulus such as vortexing the males after training, whereas changes in behavior that are associative, such as learning to avoid virgins of a certain age, are not disrupted (Ejima et al. 2005).

The neuronal circuitry underlying this form of plasticity has not been extensively examined. Habituation is often thought of as occurring in very peripheral parts of a sensory circuit, but the suppression of courtship to young males can be blocked by manipulation of more central structures, e.g., by chemical ablation of the mushroom bodies or depletion of the neuromodulators dopamine (Neckameyer 1998) and octopamine (O'Dell 1994). Mutation of the amnesiac gene, which encodes a putative neuropeptide that is expressed in a subset of neurons innervating the mushroom body, causes the memory of experience with a young male to decay more quickly (Gailey et al. 1982), further implicating mushroom bodies in this behavior. Mutations in other genes, notably dunce and rutabaga (Gailey et al. 1982), and normal aging (Neckameyer et al. 2000) also block this habituation. These studies suggest that while the response to young males is nonassociative, it is not due purely to peripheral sensory neuron desensitization.

\section{Enhancement of courtship behavior after exposure to females: Sensitization?}

Most plasticity studied with respect to male courtship behavior has involved situations that induce a male to decrease his courtship activity. In contrast, for females, enhancement of sexual receptivity has been shown to occur. This increase is caused by a sensitization process called "acoustic priming" (Kyriacou and Hall 1984; Griffith et al. 1993). Interestingly, males may also show a form of priming, based on olfactory rather than auditory input. In a study by Dukas (2005), exposure of a male to either a mated female or to an immature virgin increased courtship of a subsequently presented mature virgin. On the face of it, this study would seem to indicate that males do not learn to suppress courtship after experiencing mated females, but an examination of the experimental conditions suggests a different and more interesting explanation. Dukas used, for both training and testing, a 40-mL food vial. While affording a "more natural" and more open arena, a chamber this large reduces absolute courtship levels, especially of mated females. Indeed, Dukas reported courtship indices (percent time spent in courtship) with mated females of about $7 \%$ for naïve males. In most learning experiments done in our laboratory, this would be considered below the level necessary for effective training (we find that a courtship index of $<10 \%$ during training does not produce memory; also see Table 1 as well as Siegel and Hall [1979]). This is likely because cVA, the un- conditioned stimulus, is of relatively low volatility, and the male needs to spend time close to the mated female to be adequately exposed.

So why does being in a big vial with females cause an increase in subsequent courtship? One possibility is that there are other chemical compounds on females (mature-mated and immature) that cause a sensitization of the response to stimulatory pheromone. In the big chamber these compounds would have to be sensed at a distance, since the level of courtship of the mated female is low. This could occur either with compounds that are deposited on the vial by the female and sensed by the male using gustatory receptors or with compounds that have a higher volatility than cVA and can be sensed at a distance. Preliminary data from our laboratory (S Pashkovski and LC Griffith, unpubl.) suggest the latter may be the case, since activation of neurons that express the "fly odor" receptors Or47b and Or88a with channelrhodopsin (Zhang et al. 2007) in the absence of a courtship object can enhance subsequent courtship of virgins. The identification of the mechanism of this type of sensitization will provide another interesting and ethologically relevant form of courtship plasticity.

\section{Summary and future directions}

The study of reproductive behavior is endlessly fascinating. The colorful and sometimes strange variety of strategies that species adopt to propagate can provide hours of entertainment to the casual observer and years of entertainment for the behavioral biologist. While each species has behaviors that are effective for its selective reproduction, these behaviors are not fixed action patterns. It is advantageous for an individual animal to be able to adapt to specific sets of environmental conditions or sensory inputs and optimize its reproductive success. As biologists we often seek to reduce the complexity of a behavior by constraining conditions and inputs, and this is useful for teasing apart particular mechanisms. While obtaining an understanding of part of a behavior is satisfying, the temptation to think that this part of the behavior is going to be central to what the animal is doing or thinking under all conditions must be avoided. Behavior is above all context-dependent.

In Drosophila melanogaster we have a relatively deep understanding of some of the molecular basics of how courtship circuitry is set up. At the behavioral level, however, the apparent simplicity of our understanding breaks down. Male flies can learn to modify their behavior using inputs from all their sensory systems, and they can learn from their own performance: They can form associative memories; they can habituate; they can sensitize. All of these processes can be in play at the same time, making a mechanistic understanding of a particular event challenging without considering it from a systems point of view. The richness and depth of plasticity in courtship behavior may provide an opportunity to begin to think about this kind of complexity at a different level.

\section{Acknowledgments}

We thank K.K. Siwicki and J.C. Hall for helpful and insightful comments.

\section{References}

Ackerman SL, Siegel RW. 1986. Chemically reinforced conditioned courtship in Drosophila: Responses to wild-type and the dunce, amnesiac and don giovanni mutants. J Neurogenet 3: 111-123.

Bastock M, Manning A. 1955. The courtship of Drosophila melanogaster. Behaviour 8: 85-111.

Berry J, Krause WC, Davis RL. 2008. Olfactory memory traces in Drosophila. Prog Brain Res 169: 293-304. 
Bragina YV, Kamyshev NG. 2003. Comparative studies of four Drosophila P-insertion mutants with memory defects. Neurosci Behav Physiol 33: 73-79.

Bray S, Amrein H. 2003. A putative Drosophila pheromone receptor expressed in male-specific taste neurons is required for efficient courtship. Neuron 39: 1019-1029.

Broughton SJ, Tully T, Greenspan RJ. 2003. Conditioning deficits of CaMkinase transgenic Drosophila melanogaster in a new excitatory courtship assay. J Neurogenet 17: 91-102.

Burnet B, Connolly K, Dennis L. 1971. The function and processing of auditory information in the courtship behaviour of Drosophila melanogaster. Anim Behav 19: 409-415.

Butterworth FM. 1969. Lipids of Drosophila: A newly detected lipid in the male. Science 163: 1356-1357.

Clyne JD, Miesenbock G. 2008. Sex-specific control and tuning of the pattern generator for courtship song in Drosophila. Cell 133: 354-363.

Cook R, Cook A. 1975. The attractiveness to males of female Drosophila melanogaster: Effects of mating, age and diet. Anim Behav 23: 521526.

Cowan TM, Siegel RW. 1984. Mutational and pharmacological alterations of neuronal membrane function disrupt conditioning in Drosophila. J Neurogenet 1: 333-344.

Davis RL. 2005. Olfactory memory formation in Drosophila: From molecular to systems neuroscience. Annu Rev Neurosci 28: 275-302.

Diagana TT, Thomas U, Prokopenko SN, Xiao B, Worley PF, Thomas JB. 2002. Mutation of Drosophila homer disrupts control of locomotor activity and behavioral plasticity. J Neurosci 22: 428-436.

Donlea JM, Ramanan N, Shaw PJ. 2009. Use-dependent plasticity in clock neurons regulates sleep need in Drosophila. Science 324: 105-108.

Duffy JB. 2002. GAL4 system in Drosophila: A fly geneticist's Swiss army knife. Genesis 34: 1-15.

Dukas R. 2005. Experience improves courtship in male fruit flies. Anim Behav 69: 1203-1209.

Eberl DF, Duyk GM, Perrimon N. 1997. A genetic screen for mutations that disrupt an auditory response in Drosophila melanogaster. Proc Natl Acad Sci 94: $14837-14842$.

Ejima A, Griffith LC. 2008. Courtship initiation is stimulated by acoustic signals in Drosophila melanogaster. PLoS One 3: e3246. doi: 10.1371/ journal.pone.0003246.

Ejima A, Griffith LC. 2009. Multimodal sensory integration of courtship stimulating cues in Drosophila melanogaster: Contextual effects on chemosensory cues. Ann N Y Acad Sci 1170: 394-398.

Ejima A, Smith BP, Lucas C, Levine JD, Griffith LC. 2005. Sequential learning of pheromonal cues modulates memory consolidation in trainer-specific associative courtship conditioning. Curr Biol 15: 194-206.

Ejima A, Smith BP, Lucas C, van der Goes van Naters W, Miller CJ, Carlson JR, Levine JD, Griffith LC. 2007. Generalization of courtship learning in Drosophila is mediated by cis-vaccenyl acetate. Curr Biol 17: 599-605.

Ferveur JF. 2005. Cuticular hydrocarbons: Their evolution and roles in Drosophila pheromonal communication. Behav Genet 35: 279-295.

Gailey DA, Jackson FR, Siegel RW. 1982. Male courtship in Drosophila: The conditioned response to immature males and its genetic control. Genetics 102: 771-782.

Gailey DA, Jackson FR, Siegel RW. 1984. Conditioning mutations in Drosophila melanogaster affect an experience-dependent behavioral modification in courting males. Genetics 106: 613-623.

Gailey DA, Hall JC, Siegel RW. 1985. Reduced reproductive success for a conditioning mutant in experimental populations of Drosophila melanogaster. Genetics 111: 795-804.

Gailey DA, Lacaillade RC, Hall JC. 1986. Chemosensory elements of courtship in normal and mutant, olfaction-deficient Drosophila melanogaster. Behav Genet 16: 375-405.

Gailey DA, Villella A, Tully T. 1991. Reassessment of the effect of biological rhythm mutations on learning in Drosophila melanogaster. J Comp Physiol [A] 169: 685-697.

Ganguly-Fitzgerald I, Donlea J, Shaw PJ. 2006. Waking experience affects sleep need in Drosophila. Science 313: 1775-1781.

Griffith LC. 2004. Calcium/calmodulin-dependent protein kinase II: An unforgettable kinase. J Neurosci 24: 8391-8393.

Griffith LC, Verselis LM, Aitken KM, Kyriacou CP, Greenspan RJ. 1993. Inhibition of calcium/calmodulin-dependent protein kinase in Drosophila disrupts behavioral plasticity. Neuron 10: 501-509.

Griffith LC, Wang J, Zhong Y, Wu CF, Greenspan RJ. 1994. Calcium/ calmodulin-dependent protein kinase II and potassium channel subunit eag similarly affect plasticity in Drosophila. Proc Natl Acad Sci 91: $10044-10048$.

Grillet M, Dartevelle L, Ferveur JF. 2006. A Drosophila male pheromone affects female sexual receptivity. Proc Biol Sci 273: 315-323.

Hall JC. 1994. The mating of a fly. Science 264: 1702-1714.

Ishimoto H, Sakai T, Kitamoto T. 2009. Ecdysone signaling regulates the formation of long-term courtship memory in adult Drosophila melanogaster. Proc Natl Acad Sci 106: 6381-6386.
Jallon JM. 1984. A few chemical words exchanged by Drosophila during courtship and mating. Behav Genet 14: 441-478.

Jallon JM, Hotta Y. 1979. Genetic and behavioral studies of female sex appeal in Drosophila. Behav Genet 9: 257-275.

Joiner MA, Griffith LC. 1997. CaM kinase II and visual input modulate memory formation in the neuronal circuit controlling courtship conditioning. J Neurosci 17: 9384-9391.

Joiner MA, Griffith LC. 1999. Mapping of the anatomical circuit of CaM kinase-dependent courtship conditioning in Drosophila. Learn Mem 6: 177-192.

Joiner MA, Griffith LC. 2000. Visual input regulates circuit configuration in courtship conditioning of Drosophila melanogaster. Learn Mem 7: 32-42.

Kamyshev NG, Iliadi KG, Bragina JV. 1999. Drosophila conditioned courtship: Two ways of testing memory. Learn Mem 6: 1-20.

Kamyshev NG, Iliadi KG, Bragina YV, Savvateeva-Popova EV, Tokmacheva EV, Preat T. 2000. Identification of Drosophila mutant with memory defects after acquisition of conditioned reflex suppression of courtship. Neurosci Behav Physiol 30: 307-313.

Kamyshev NG, Iliadi KG, Bragina JV, Kamysheva EA, Tokmatcheva EV, Preat T, Savvateeva-Popova EV. 2002. Novel memory mutants in Drosophila: Behavioral characteristics of the mutant nemy ${ }^{P 153}$. BMC Neurosci 3: 9. doi: 10.1186/1471-2202-3-9.

Kane NS, Robichon A, Dickinson JA, Greenspan RJ. 1997. Learning without performance in PKC-deficient Drosophila. Neuron 18: 307-314.

Keleman K, Kruttner S, Alenius M, Dickson BJ. 2007. Function of the Drosophila CPEB protein Orb2 in long-term courtship memory. Nat Neurosci 10: 1587-1593.

Krstic D, Boll W, Noll M. 2009. Sensory integration regulating male courtship behavior in Drosophila. PLoS One 4: e4457. doi: 10.1371/ journal.pone.0004457.

Kurtovic A, Widmer A, Dickson BJ. 2007. A single class of olfactory neurons mediates behavioural responses to a Drosophila sex pheromone. Nature 446: $542-546$.

Kyriacou CP, Hall JC. 1984. Learning and memory mutations impair acoustic priming of mating behaviour in Drosophila. Nature 308: 62-65.

Lacaille F, Hiroi M, Twele R, Inoshita T, Umemoto D, Maniere G, MarionPoll F, Ozaki M, Francke W, Cobb M, et al. 2007. An inhibitory sex pheromone tastes bitter for Drosophila males. PLoS One 2: e661. doi: 10.1371/journal.pone.000061.

Lasbleiz C, Ferveur JF, Everaert C. 2006. Courtship behavior of Drosophila melanogaster revisited. Anim Behav 72: 1001-1012.

Manoli DS, Foss M, Villella A, Taylor BJ, Hall JC, Baker BS. 2005. Malespecific fruitless specifies the neural substrates of Drosophila courtship behaviour. Nature 436: 395-400.

Margulies C, Tully T, Dubnau J. 2005. Deconstructing memory in Drosophila. Curr Biol 15: R700-R713. doi: 10.1016/j.cub.2005.08.024.

Markow TA. 1987. Behavioral and sensory basis of courtship success in Drosophila melanogaster. Proc Natl Acad Sci 84: 6200-6204.

McBride SM, Giuliani G, Choi C, Krause P, Correale D, Watson K, Baker G, Siwicki KK. 1999. Mushroom body ablation impairs short-term memory and long-term memory of courtship conditioning in Drosophila melanogaster. Neuron 24: 967-977.

McBride SM, Choi CH, Wang Y, Liebelt D, Braunstein E, Ferreiro D, Sehgal A, Siwicki KK, Dockendorff TC, Nguyen HT, et al. 2005. Pharmacological rescue of synaptic plasticity, courtship behavior, and mushroom body defects in a Drosophila model of fragile X syndrome. Neuron 45: 753764.

McGaugh JL. 2000. Memory—a century of consolidation. Science 287: 248251.

Mehren JE, Griffith LC. 2004. Calcium-independent calcium/calmodulindependent protein kinase II in the adult Drosophila CNS enhances the training of pheromonal cues. J Neurosci 24: 10584-10593.

Mehren JE, Griffith LC. 2006. Cholinergic neurons mediate CaMKIIdependent enhancement of courtship suppression. Learn Mem 13: 686689.

Neckameyer WS. 1998. Dopamine and mushroom bodies in Drosophila: Experience-dependent and -independent aspects of sexual behavior. Learn Mem 5: 157-165.

Neckameyer WS, Woodrome S, Holt B, Mayer A. 2000. Dopamine and senescence in Drosophila melanogaster. Neurobiol Aging 21: 145-152.

O'Dell KM. 1994. The inactive mutation leads to abnormal experiencedependent courtship modification in male Drosophila melanogaster. Behav Genet 24: 381-388.

O'Dell KM, Jamieson D, Goodwin SF, Kaiser K. 1999. Abnormal courtship conditioning in males mutant for the RI regulatory subunit of Drosophila protein kinase A. J Neurogenet 13: 105-118.

Presente A, Boyles RS, Serway CN, de Belle JS, Andres AJ. 2004. Notch is required for long-term memory in Drosophila. Proc Natl Acad Sci 101: 1764-1768.

Reif M, Linsenmair KE, Heisenberg M. 2002. Evolutionary significance of courtship conditioning in Drosophila melanogaster. Anim Behav 63: 143155. 
Sakai T, Kidokoro Y. 2002. Overexpression of a CREB repressor isoform enhances the female sexual receptivity in Drosophila. Behav Genet 32: 413-422.

Sakai T, Tamura T, Kitamoto T, Kidokoro Y. 2004. A clock gene, period, plays a key role in long-term memory formation in Drosophila. Proc Natl Acad Sci 101: 16058-16063.

Savarit F, Sureau G, Cobb M, Ferveur JF. 1999. Genetic elimination of known pheromones reveals the fundamental chemical bases of mating and isolation in Drosophila. Proc Natl Acad Sci 96: 9015-9020.

Savvateeva E, Popov A, Kamyshev N, Bragina J, Heisenberg M, Senitz D, Kornhuber J, Riederer P. 2000. Age-dependent memory loss, synaptic pathology and altered brain plasticity in the Drosophila mutant cardina accumulating 3-hydroxykynurenine. J Neural Transm 107: 581-601.

Scott D, Richmond RC, Carlson DA. 1988. Pheromones exchanged during mating: A mechanism for mate assessment in Drosophila. Anim Behav 36: 1164-1173.

Siegel RW, Hall JC. 1979. Conditioned responses in courtship behavior of normal and mutant Drosophila. Proc Natl Acad Sci 76: 565-578.

Sitnik NA, Tokmacheva EV, Savvateeva-Popova EV. 2003. The ability of Drosophila mutants with defects in the central complex and mushroom bodies to learn and form memories. Neurosci Behav Physiol 33: 67-71.

Siwicki KK, Riccio P, Ladewski L, Marcillac F, Dartevelle L, Cross SA, Ferveur JF. 2005. The role of cuticular pheromones in courtship conditioning of Drosophila males. Learn Mem 12: 636-645.

Spieth HT. 1974. Courtship behavior in Drosophila. Annu Rev Entomol 19: 383-406.

Stockinger P, Kvitsiani D, Rotkopf S, Tirian L, Dickson BJ. 2005. Neural circuitry that governs Drosophila male courtship behavior. Cell 121: 795-807.

Strauss R. 2002. The central complex and the genetic dissection of locomotor behaviour. Curr Opin Neurobiol 12: 633-638.

Tauber E, Eberl DF. 2003. Acoustic communication in Drosophila. Behav Processes 64: 197-210.

Tompkins L, Hall JC, Hall LM. 1980. Courtship-stimulating volatile compounds from normal and mutant Drosophila. J Insect Physiol 26: 689-697.
Tompkins L, Siegel RW, Gailey DA, Hall JC. 1983. Conditioned courtship in Drosophila and its mediation by association of chemical cues. Behav Genet 13: 565-578.

Tully T, Preat T, Boynton SC, Del Vecchio M. 1994. Genetic dissection of consolidated memory in Drosophila. Cell 79: 35-47.

Vaias LJ, Napolitano LM, Tompkins L. 1993. Identification of stimuli that mediate experience-dependent modification of homosexual courtship in Drosophila melanogaster. Behav Genet 23: 91-97.

van der Goes van Naters W, Carlson JR. 2007. Receptors and neurons for fly odors in Drosophila. Curr Biol 17: 606-612.

Villella A, Hall JC. 2008. Neurogenetics of courtship and mating in Drosophila. Adv Genet 62: 67-184.

von Schilcher F. 1976a. The function of pulse song and sine song in the courtship of Drosophila melanogaster. Anim Behav 24: 622-625.

von Schilcher F. 1976b. The role of auditory stimuli in the courtship of Drosophila melanogaster. Anim Behav 24: 18-26.

Wicker C, Jallon J-M. 1995. Hormonal control of sex pheromone biosynthesis in Drosophila melanogaster. J Insect Physiol 41: 65-70.

Yew JY, Dreisewerd K, Luftmann H, Muthing J, Pohlentz G, Kravitz EA. 2009. A new male sex pheromone and novel cuticular cues for chemical communication in Drosophila. Curr Biol 19: 1245-1254.

Zawistowski S. 1988. A replication demonstrating reduced courtship of Drosophila melanogaster by associative learning. J Comp Psychol 102: 174-176.

Zawistowski S, Richmond RC. 1985. Experience-mediated courtship reduction and competition for mates by male Drosophila melanogaster. Behav Genet 15: 561-569.

Zawistowski S, Richmond RC. 1986. Inhibition of courtship and mating of Drosophila melanogaster by the male-produced lipid, cis-vaccenyl acetate. J Insect Physiol 32: 189-192.

Zhang F, Aravanis AM, Adamantidis A, de Lecea L, Deisseroth K. 2007. Circuit-breakers: Optical technologies for probing neural signals and systems. Nat Rev Neurosci 8: 577-581.

Received August 4, 2009; accepted in revised form September 11, 2009. 


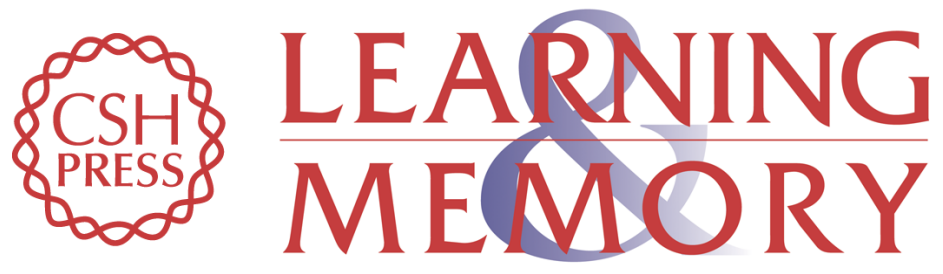

\title{
Courtship learning in Drosophila melanogaster: Diverse plasticity of a reproductive behavior
}

\author{
Leslie C. Griffith and Aki Ejima
}

Learn. Mem. 2009, 16:

Access the most recent version at doi:10.1101//m.956309

References This article cites 89 articles, 23 of which can be accessed free at:

http://learnmem.cshlp.org/content/16/12/743.full.html\#ref-list-1

License

Email Alerting Receive free email alerts when new articles cite this article - sign up in the box at the Service top right corner of the article or click here. 